\title{
A Pragmatic Study on College EFL Teachers' and Students' Requesting Behaviors in the Classrooms
}

\author{
Chiung-Chiuen Chen and David S. D. Tseng
}

\begin{abstract}
Many of the studies on $\mathbf{L} 2$ requesting behaviors have focused on $L 2$ speakers' uses of request strategy types, lacking of explorations of various and complex pragmatic functions of requests. This study examined college EFL teachers' and students' requesting behaviors from a pragmatic perspective. Five teachers from different universities in Taiwan were invited to participate in the study. The study found that all teachers and students made direct and indirect requests and performed various pragmatic functions of requests. In direct requests, the teachers tended to use the imperative and locution derivable type, and in indirect requests, the query preparatory type. The students tended to use the locution derivable and query preparatory type. In pragmatic functions, all teachers made requests for information, confirmation, clarification, offer, control, advice, attention, ability, speculation, encouragement, and attention. The students made requests for clarification, want/need, permission, desire/wish, suggestion, help, curiosity, confirmation, offer, and advice. This study is of significance to provide a comprehensive understanding of the teachers' and students' language uses of requests as well as their performance of pragmatic functions in requests in the EFL classroom. Based upon the findings of the study, some pedagogical implications and suggestions are made.
\end{abstract}

Index Terms - Requesting behavior, teacher request, student request, pragmatic functions of requests.

\section{INTRODUCTION}

The purposes of the study are to examine college EFL teachers' and students' requesting behaviors in the English classrooms from a pragmatic perspective. Requesting, seen as a complex sociolinguistic phenomenon, has been much researched in the field of sociolinguistics and pragmatics in which it is assumed that people make requests for performing certain pragmatic functions in social contexts [1]-[5]. Requesting also occurs in the language classrooms where both teachers and students make requests for various pragmatic purposes across different situations [6]-[8]. In the classroom settings, most of the studies [6], [8], [9] have concentrated on L2 teachers' and students' uses of linguistic forms and strategies in requests. Although these studies have also found certain pragmatic functions of teacher and student requests (e.g., a request for clarification), the findings seem to be limited in their range, quality, and quantity of investigation.

This study has theoretically and pedagogically significance.

Manuscript received August 10, 2015; revised November 25, 2015.

Chiung-Chiuen Chen is with National Changhua University of Education, Taiwan (e-mail: brendaa@ms3.hinet.net).

David S. D. Tseng is with Providence University, Taiwan. He was with National Changhua University of Education, Taiwan (e-mail: sdtseng@gmail.com).
First, it is of great significance to do in-depth research into teacher and student requests from the pragmatic perspective. Second, to give L2 teachers insight into the pragmatic view of a request in pedagogical applications for the improvements of college EFL students' ability in requests, it is of significance to explore the types of teacher and student requests as well as pragmatic functions performed in requests in the EFL classrooms.

\section{LITERATURE REVIEW}

\section{A. Research on Requests in Sociolinguistic Studies}

Requesting behaviors have been seen as a typical sociolinguistic behavior [10]. Theoretically, it is assumed that people make requests for performing various pragmatic functions or purposes in different social contexts [3]. For example, the performance "Can you pass the salt?" is regarded as a request made for help rather than as a request for asking one's potential ability [11] in certain contexts. The performance of the same request type (e.g., "What time is it?") may serve as more than one pragmatic function. A speaker may make a request to give an order, to encourage people to work, to express wishes, to get information, to warn, and to complain [3]. The pragmatic functions performed in requests vary depending on different social contexts.

Requesting behaviors have been much researched in the field of sociolinguistics and pragmatics. Much research finds that native and non-native English speakers use both direct and indirect requests in different social contexts [12]-[16]. These studies examine speakers' uses of request types at the directness level. Cross-cultural studies on requests have also found that both native and non-native English speakers use direct and indirect requests in different social situations. Many studies [17]-[22] have investigated and compared the request types employed by native and non-native English speakers with different L1 backgrounds. Among these studies, the most well-known investigation is the Cross-Cultural Speech Act Realization Project (CCSARP) [1], [17], in which the research focus is on comparing the uses of request strategy types between L1 speakers and L2 speakers in different social situations [4], [14], [21]-[24].

\section{B. Research on Requests by Chinese Learners of English}

There have been several studies investigating requests by Chinese learners of English. Many researches [2], [4], [21], [25] find that Chinese ESL/EFL learners use both direct requests and indirect requests in different social situations. [4], [25] studies compare the requests made between Chinese college EFL students and native speakers of American 
English, examining how the social factors (social status, familiarity, and degree of imposition) affect the speakers' choices of requests across different situations (e.g., students ask for an extension on paper deadlines from professors, students ask to take a leave from professors, and, students ask to borrow notes from classmates). In Yu's studies, Chinese EFL learners use more direct requests than the native speakers of American English although conversely they use less non-conventional indirect requests than their counterparts. [25] explains that it is possible that Chinese learners' limited ability in English and their L1 transfer as well as the cultural factor lead to the difference in requesting behaviors between these two groups.

Ref. [4] conducts an empirical study to compare Chinese (Taiwanese) college EFL students' use of indirect request strategies and linguistic forms to native speakers of English across 20 situations. The findings show that college EFL students in Taiwan overuse the conventional indirect requests "will I/ you and would I/ you," "may I/you" and "can I/ you and could $\mathrm{I} /$ you" in most of the social situations whereas the native speakers of English use them only in some situations. As exploring the request types from the speaker-oriented and hearer-oriented perspectives, for instance, in the "borrowing book" situation, the findings reveal that college EFL students frequently use the hearer-oriented types "Can you share your book to me?" different from the native speakers of English who tend to use the speaker-oriented types "Can I share with you?" (p. 1651). Lin indicates that college EFL students had limited ability to use indirect requests, for example, their uses of "Would you like to write a recommendation letter for me?", "William, would you like to lend me your motorcycle?" (I would like to ask you) and "Jason, would you like to do me a favor?", "I'm going to move to another dorm this weekend," and "I can't move all the stuff by myself," and "I need your help!" [4]. The first two expressions belong to the direct request types. That is, "would you like to ..." means "I would like to ask you to..." and the third one "I need your help" is a direct request (want/need statement) subtype. These studies note the Chinese college EFL students' limited abilities to use indirect requests.

\section{Research on Teachers' Requesting Behaviors in the English Classrooms}

Teachers make requests in the ESL/EFL classrooms. Previous studies [8], [26]-[30] reveal that teachers make two types of requests: the direct requests and the indirect requests. Some studies [28]-[29] find that English teachers appear to use direct requests more than the indirect ones, whereas other studies [8], [30] show results to the contrary. [28] find that in the ESL classrooms teachers' requests are mostly direct by employing "imperatives" (one type of request strategy) due to pedagogical purposes. [8] examines teacher requests and student requests in the EFL content-and-language-integrated-learning (CLIL) classrooms where English is used as the instructional medium at secondary schools in Austria. The findings show that secondary school EFL teachers tend to use indirect requests more than direct requests for goods and services. [8] finds many instances of teachers' uses of indirect requests such as "Can you take out these sheets of paper?", "Let's look at the social structure", "Would you like to do it please?", "Could anybody please just quickly tell me...?", and "May I ask a question in between?" (p. 1285). Dalton-Puffer notes only a few instances of direct teacher requests, e.g., "Think about that question for 30 seconds", "Ok, ...go on" and "you must return it according to your catalog number" (p. 1284). In terms of the types of request strategies, the findings in [8] show that teachers use different request subtypes including the "imperative," "elliptical phrase," "obligation," "wish," "desire/need," "permission," "willingness," “ability," and "hint" subtypes (p. 1284). In conformity with Dalton-Puffer's findings, [30] find that Japanese English teachers appear to use more indirect requests in the English classrooms, compared to the classrooms where Japanese is the medium of instruction. In terms of linguistic types in requests, the findings in Ref. [26] and Ref. [27] show that English teachers use more "interrogative type" of request (i.e. requesting by asking questions) [31]. Teacher requests vary in the English classrooms. According to [8], teachers' uses of request types may be related to certain speech functions in requests such as request for information and request for command.

L2 teachers make requests for performing specific pragmatic functions in the classroom, too [31]-[33]. According to [31], "teachers' questions constitute a primary means of engaging learners' attention, promoting verbal responses, and evaluating learners' progress" (p. 126). Teacher questions serve pragmatic functions. For example, "Pardon?" is seen as a request for clarification. [31] notes three major types of teacher requests in terms of pragmatic functions: comprehension checks, confirmation checks, and clarification requests. According to [32], teachers may request for clarification and repetition in the English classrooms. Previous studies [8], [26]-[29] found certain types of pragmatic functions in teacher requests in the ESL/EFL classrooms. The findings in [28] and [34] reveal that the teachers appear to use more "comprehension checks" than confirmation checks and clarification requests in teacher-student classroom interaction. However, their findings show that in the group task, the teachers use more "confirmation checks" than "comprehension checks." The findings also reveal that the teachers tend to use less "clarification requests" in both classroom interaction and the group task. In contrast to the findings in [28], [34], [27] finds that teachers use only "comprehension checks" in most of the classroom situations [34] (p.131). Ref. [8] notes certain pragmatic functions (using the term, "speech function" or "request goal") in teacher requests, including requests for information, and requests for goods and services (actions, goods, and permission). In Dalton-Puffer's findings, the pragmatic functions of requests serve mostly as request for information such as "... city what kind of cities do you know about in the east in America?", and "...the husband administers it, yeah? He can do with it what he likes, but in case of divorce?" (p. 1283). The examples of requests for goods and services in [8] are "you must return it according to your catalog number, so that you're not in trouble," "good, could you think about three factors that changed for women dramatically in this period?" (p. 1285). Ref. [8] finds that the teachers use either the indirect request such as "Would you like to continue?", "Good, could you think about three factors 
that changed for women dramatically in this period" or the direct request such as "Think about that question for 30 seconds" for performing requests for goods and services ( $p$. 1285).

\section{Research on Students' Requesting Behaviors in the English Classrooms}

Students make requests in the English classrooms, too. Research has found that students make different types of requests, including the direct type and the indirect type, in the ESL/EFL classrooms [6], [8], [35]. Ref. [6] observes two ESL children's development of the use of requests in terms of the level of directness in the classrooms. His findings show that that his subjects tend to use the direct requests by using the imperative (e.g., "Give me my paper"), want statement (e.g., "Miss, I want the stapler"), and elliptical phrase subtypes (e.g., "Sir, sir, sir pencil"), and use the indirect requests by using the "query preparatory" subtype (e.g., "Can I take book with me?"). Ref. [6] finds that they do not use the performative (e.g., "I am asking you to ..."), obligation statement (e.g., "You'll have to..."), suggestory formula (e.g., "How about...?"), and "hint" subtypes, which are identified by [1]. In addition, the polite marker, "please", is seldom used. According to Ellis, the students do not develop a full range of request types because the classroom offers little opportunity for them to perform requests.

Students also make requests for performing specific pragmatic functions in different classroom contexts. Several studies [6], [9], [36], [37] have found that students perform different pragmatic functions of requests in the classroom, for instance, request for comprehension, confirmation, and clarification either in group or in teacher-fronted discussion in the English classrooms. [37] findings reveal that students make requests for confirmation and clarification more in peer interaction than in teacher-fronted interaction. Ellis' findings show that ESL students make requests for object, permission, help, need and wish in the classrooms. He notes that L2 learners' requests seem to be "functionally driven." Although such observational studies reveal certain pragmatic functions of requests in different classroom situations, the research evidence seems insufficient to explain the complex process of requests by learners in the EFL classrooms.

\section{RESEARCH QUESTIONS}

1) What types of requests do college EFL teachers and students make in the English classroom?

2) What pragmatic functions of requests are performed by college EFL teachers and students in the English classroom?

\section{RESEARCH DESIGN}

\section{A. Participants}

Five Chinese-speaking female college EFL teachers (pseudo-named Teacher A, B, C, D, and E) from different universities in central Taiwan were invited to participate in the study. They had at least five years of Freshman English teaching experience. Their teaching styles were communication-oriented and they used English as the instructional medium. Their English courses - utilizing both lecture and group work - mainly aimed at developing students' communicative competence, covering the development of four language skills - listening, speaking, reading, and writing. All teachers used four-skill based teaching materials.

The student participants consisted of five intact classes of Freshman English at five different universities in central Taiwan. None of the students were English majors. They were required to take the Freshman English for one academic year (two hours per week at four universities, and three hours per week at the fifth university for a total of 18 weeks per semester), to fulfill their graduation requirements.

\section{B. Data Collection}

The study used classroom observation as the method for data-collection. The purpose of classroom observation was to examine teachers' and students' actual requesting behaviors in the college EFL classrooms. Over a 4-week period, two lesson units of teaching were observed, video-taped, and audio-taped for each class. A total of 39 periods, 50 minutes each, were observed.

\section{Data Analysis}

In this study, a framework of analysis (see Appendix) was developed to analyze college EFL teachers' and students' requesting behaviors in the English classrooms. The analysis consists of requests in terms of the levels of directness and pragmatic functions of requests performed.

In this study, the categorization of requests at the directness level was based on previous taxonomies by [1], [23], [24]. Two major types are direct and indirect requests. The direct request was further divided into six subtypes, consisting of the imperative (including the mood derivable type), unhedged performative, hedged performative, locution derivable (including the obligation type), want statement, and elliptical phrase subtypes. The indirect request was subcategorized into five subtypes: the suggestory formula, query preparatory (including the ability, permission, and willingness type), wish/desire, strong hint, and mild hint subtypes. This categorization was developed by considering its suitability and applicability to the current study. The categorization of pragmatic functions of requests performed by teachers and students was based on the theories in pragmatics and findings by [6], [28], [31].

The request types at the directness level were coded basing on the definitions and examples in [1], [4], [15], [21], [24], [28]. The request types in terms of pragmatic functions by teachers and students were coded with respect to the definitions and examples presented in previous studies [8], [38], [39]. The occurrences of various types of teacher and student requests at the directness level, and the performance of pragmatic functions in requests were calculated.

\section{Reliability}

Firstly, the test-retest reliability in coding was calculated. The teacher and student request types at the directness levels and pragmatic functions were coded twice. For the first time, coding was done from the transcription with Teacher A to Teacher E. For the second time, coding was done by teaching 
sessions across teachers in the data. That is, the first session of Teacher A was coded, next, of Teacher B, then, of Teacher C, Teacher D, and Teacher E. The discrepancy of the two codings was triangulated and finalized by the teachers who participated in the study. The test-retest reliability, $88 \%$, was attained.

Secondly, the inter-rater reliability was also calculated. A sample of twenty percent of the data was coded by the researcher and one college EFL teacher with experiences in teaching Freshman English. The inter-rater reliability was $89.7 \%$. The discrepancy of the data coding of the researcher and the second rater was triangulated and finalized by the teachers who participated in the study.

\section{RESULTS AND DISCUSSION}

The results showed that all teachers made use of both direct and indirect requests. Table I shows the frequencies of teacher request types at the directness level in the English classrooms.

TABLE I: FREQUENCIES OF REQUESTS BY TEACHERS IN TERMS OF REQUEST

\begin{tabular}{llllll}
\multicolumn{7}{c}{ TYPES AT THE DIRECTNESS LEVEL } \\
\hline Types & $\mathrm{A}$ & $\mathrm{B}$ & $\mathrm{C}$ & $\mathrm{D}$ & $\mathrm{E}$ \\
\hline Direct Requests & $66 \%$ & $73 \%$ & $53 \%$ & $62 \%$ & $75 \%$ \\
Imperative & $41 \%$ & $32 \%$ & $33 \%$ & $39 \%$ & $10 \%$ \\
$\quad \begin{array}{l}\text { Unhedged } \\
\text { performative }\end{array}$ & $1 \%$ & $21 \%$ & $2 \%$ & $0 \%$ & $1 \%$ \\
$\quad$ Hedged & $1 \%$ & $0 \%$ & $1 \%$ & $0 \%$ & $1 \%$ \\
performative & & & & & \\
Locution derivable & $42 \%$ & $47 \%$ & $44 \%$ & $29 \%$ & $64 \%$ \\
Want statement & $1 \%$ & $3 \%$ & $1 \%$ & $3 \%$ & $1 \%$ \\
$\quad$ Elliptical phrase & $14 \%$ & $18 \%$ & $17 \%$ & $29 \%$ & $22 \%$ \\
Indirect Requests & $34 \%$ & $27 \%$ & $47 \%$ & $38 \%$ & $25 \%$ \\
$\quad$ Suggestory formula & $21 \%$ & $6 \%$ & $20 \%$ & $18 \%$ & $14 \%$ \\
Query preparatory & $64 \%$ & $74 \%$ & $55 \%$ & $55 \%$ & $72 \%$ \\
Desire/wish & $15 \%$ & $20 \%$ & $23 \%$ & $26 \%$ & $10 \%$ \\
$\quad$ Strong hint & $1 \%$ & $1 \%$ & $1 \%$ & $1 \%$ & $1 \%$ \\
Mild hint & $0 \%$ & $0 \%$ & $1 \%$ & $0 \%$ & $0 \%$ \\
\hline
\end{tabular}

As can be seen from Table I all teachers used more direct requests $(66 \%, 73 \%, 53 \%, 62 \%$, and $75 \%$ respectively) than indirect requests $(34 \%, 27 \%, 47 \%, 38 \%$, and $25 \%$ respectively). The results showed that these teachers used different request types at the directness level. In the direct request sub-types, the imperative, locution derivable, want statement, and elliptical phrase sub-types were employed by all teachers. Although they made these request sub-types, they used a small percentage of the want statement sub-type. As illustrated in Table I, most of the teachers used a higher percentage of the imperative and locution derivable sub-type. Interestingly, Teacher $\mathrm{E}$ used a quite high percentage of the locution derivable sub-type (64\%) but a small percentage of the imperative sub-type (10\%). Table I also showed that the teachers used a high percentage of the elliptical phrase sub-type.

In the indirect sub-types, the suggestory formula, query preparatory, desire and wish, and strong hint sub-types were employed by all teachers. As shown in Table I, although all teachers made use of these request types, they used a small percentage of the strong hint sub-type. Among the indirect request sub-types, the query preparatory sub-type was used extensively, more than fifty percent, by all teachers.

The result showed that students also made both direct and indirect requests. Table II shows the frequency of student request types at the directness level in the English classrooms.

TABLE II: FREQUENCIES OF REQUESTS BY STUDENTS IN TERMS OF REQUEST TYPES AT THE DIRECTNESS LEVEL

\begin{tabular}{lccccc}
\hline Types/Teacher & $\mathrm{A}$ & $\mathrm{B}$ & $\mathrm{C}$ & $\mathrm{D}$ & $\mathrm{E}$ \\
\hline Direct Requests & $14 \%$ & $33 \%$ & $9 \%$ & $67 \%$ & $63 \%$ \\
Imperative & & $10 \%$ & & & $25 \%$ \\
Locution & $100 \%$ & $80 \%$ & $100 \%$ & & $60 \%$ \\
$\quad$ derivable & & & & $100 \%$ & $10 \%$ \\
Want statement & & $10 \%$ & & & $5 \%$ \\
$\quad$ Elliptical phrase & & $107 \%$ & $91 \%$ & $33 \%$ & $37 \%$ \\
$\begin{array}{l}\text { Indirect Requests } \\
\text { Suggestory }\end{array}$ & $86 \%$ & $67 \%$ & & & \\
$\quad$ formula & & $5 \%$ & & & \\
Query \\
preparatory & $67 \%$ & $80 \%$ & $80 \%$ & $100 \%$ & $100 \%$ \\
$\quad \begin{array}{c}\text { Desire/Wish } \\
\text { Strong hint }\end{array}$ & $33 \%$ & $5 \%$ & $20 \%$ & & \\
\hline & & $10 \%$ & & & \\
\hline
\end{tabular}

As illustrated in Table II, the direct request sub-types employed by students were the imperative, locution derivable, want statement, and elliptical phrase sub-types. The indirect request sub-types employed were the suggestory formula, query preparatory, desire and wish, and strong hint sub-types. Among these five classes, students in Teacher B's class, actually, used more request types than the other classes did. As also shown in Table II, it was found that the query preparatory sub-type was used by students in all classes. Although students made direct and indirect requests, the requests used are still rare in the English classrooms.

It is evident that direct requests are frequently made by college teachers in the EFL classroom. The results seem to confirm previous researches [28], [29] that English teachers tend to use more direct requests in the ESL/EFL classrooms. Possibly, as [28] note, L2 teachers tend to make direct requests as they emphasize more on pedagogical purposes. The other explanation is because in EFL instructional settings, teachers are likely to express themselves more directly in English for EFL students to understand their English. They make indirect requests, too. The results are in agreement with the results obtained by previous studies [8], [30]. According to Dalton-Puffer, this may be due to "the different cultural pattern with regard to how teachers construct their relationship with students" (p.1287). Besides, it is also possible that EFL teachers make indirect requests because they use their native language as the medium of instruction in the EFL classrooms. The tendency of L2 teachers' making of indirect requests seems to be influenced by their first language or their cultural patterns.

The results also reveal that college EFL teachers and students make requests by using different request types at the directness level. In the direct request types, the data of the study reveal that all teachers employ the imperative, locution derivable, want statement, and elliptical phrase sub-types. In particular, the imperative sub-type (e.g., "Read the question." and "Have a look.") and the locution derivable sub-type (e.g., "What is...?", "Who is...?", and "You have to") are frequently used. In this study, not surprisingly, the imperative sub-type is frequently used. As [15] notes, using the imperative sub-type is regarded appropriate in interactions between "higher status and lower status interlocutors", such as teacher and student. The other explanation is that in instructional settings, teachers are likely to use more imperative sub-type due to pedagogical purposes or 
classroom management. For example, they may say "turn to page...", "Look at...", or "Listen". Additionally, the results reveal that the teachers employ the locution derivable sub-type very frequently (e.g., "What does...?", "Which word ...?", "What do I just mention?", and "Why do you...?"). These results seem to confirm to those of the previous researches [40]-[42] that teachers tend to use more display questions in the L2 classroom. This indicates that in the classroom settings, teachers use such request sub-types for pedagogical purposes. Likewise, the elliptical phrase sub-type, such as "Next one, please," is also employed by all teachers. This is also used for instructional purposes. With regard to the use of the want statement sub-type in the study, one possible explanation is that teachers are concerned with their role of being responsible for teaching, so they say "I want you to" for expressing their concerns. Even though all teachers use the want statement sub-type (e.g., "I want you to"), compared to the other sub-types, it is less frequently employed. A possible reason is that they are also concerned with students' responses or their feelings in the English classrooms.

In the indirect request sub-types, the query preparatory sub-type (e.g., "Can you...?", "Do you...?", and "Does anyone...?") is frequently used by college EFL teachers in the classrooms. This result is in agreement with [8] research which shows that some indirect request types (e.g., "Would you like to...?", "Could you...?", "Can you...?", and "Have you got...?") are extensively used in the EFL classrooms. According to Dalton-Puffer, teachers tend to use such types due to their personal preferences. In the present study, it is also possible that the teachers have their preferences in the use of these types. The explanations may also relate to the individual teacher's personality and cognitive domains, and teacher beliefs [43]. Other factors are influential too, such as the social factors (e.g., familiarity) proposed by [11].

On the other hand, the results also reveal that college EFL students make direct and indirect requests in the English classrooms. But in the direct request sub-types, they tend to use the locution derivable sub-type (e.g., "What/How/Who/Which...?"), and in the indirect request sub-types, they tend to use the query preparatory sub-type (e.g., "May I...?", “Can I...?”, and "Do you...?”). These requests include those for control, attention, and order. These results are similar to the ones in [8], showing that L2 learners make requests in the classroom settings. However, these utterances by students are all used in Chinese, the learners' native language. Not surprisingly, college EFL students make requests to respond to teachers' requests in Chinese. It is likely that students are not provided enough opportunities in making requests in English in the EFL classrooms. The data of the study reveal that the students seldom respond to teacher requests in English. Some utterances used by the students in English are short or single-worded, such as "Red?" and "Video?" Even though students make requests in English, they only use one word with a rising intonation. The results seem to confirm with [21] and [25], showing that Chinese college EFL learners are limited in their knowledge of how to make requests in English. In fact, even though the students make requests in Chinese, they do not seem to vary their request types in different contexts. The explanations may relate to their personality, motivation, and personal preferences.

Table III shows the frequencies of the pragmatic functions performed in teacher requests. The findings showed that various pragmatic functions of requests were performed by teachers, including requests for information, confirmation, clarification, offer, suggestion, control, advice, ability, desire/wish, speculation, encouragement, attention, reflection, want/need, and so on (see Table III below). Among the pragmatic functions of requests, the teachers used a higher frequency of requests for information, suggestion, desire/wish, and want/need in the classroom.

\begin{tabular}{|c|c|c|c|c|c|c|c|c|c|c|}
\hline & A & & 3 & & $\mathrm{C}$ & & S & & & \\
\hline & $\mathrm{D}$ & I & $\mathrm{D}$ & I & $\mathrm{D}$ & I & $\mathrm{D}$ & I & $\mathrm{D}$ & I \\
\hline & 66 & 34 & 73 & 27 & 53 & 47 & 62 & 38 & 75 & 25 \\
\hline & $\%$ & $\%$ & $\%$ & $\%$ & $\%$ & $\%$ & $\%$ & $\%$ & $\%$ & $\%$ \\
\hline Information & 17 & & 29 & & 18 & & 7 & & 19 & \\
\hline Comprehension & & 1 & & & & 1 & & & & 5 \\
\hline Confirmation & & 2 & & 1 & & 1 & & 2 & & 2 \\
\hline Clarification & & 3 & 1 & 11 & 1 & 2 & 1 & 1 & 1 & 9 \\
\hline Perform a task & 1 & 1 & & & 1 & 1 & & & & \\
\hline Obligation & 2 & & 1 & 1 & 1 & & & & 1 & \\
\hline Willingness & & 1 & & & & & 1 & 1 & & \\
\hline Offer & & 1 & & 5 & & 2 & & 4 & & 2 \\
\hline Suggestion & & 21 & & 5 & & 20 & & 18 & & 30 \\
\hline Control & 1 & 3 & 1 & 2 & 2 & 1 & 2 & 4 & 1 & 2 \\
\hline Advice & 6 & 4 & & 7 & 7 & 1 & 1 & 1 & 3 & 1 \\
\hline Ability & & 15 & & 3 & & 3 & & 3 & 1 & 4 \\
\hline Desire/Wish & & 15 & & 50 & & 39 & & 40 & & 14 \\
\hline Speculation & 2 & 3 & 3 & 4 & 2 & 11 & 5 & & 5 & 11 \\
\hline Encouragement & 1 & 4 & 1 & 1 & 1 & 11 & 1 & 6 & 1 & 2 \\
\hline Attention & 1 & & 1 & 5 & 1 & 4 & & 1 & 2 & 4 \\
\hline Help & & & 1 & 1 & 1 & 1 & 1 & 6 & 1 & \\
\hline Accomplishment & & 1 & & & & & & & 1 & 1 \\
\hline Reflection & & 2 & 1 & 1 & 2 & 2 & 1 & & 1 & 2 \\
\hline Want/Need & 71 & 24 & 64 & & 64 & & 80 & 13 & 67 & 13 \\
\hline Cooperation & & & & & 1 & 2 & & & & 1 \\
\hline Curiosity & & & & 2 & & 1 & & & & \\
\hline Greetings & & & & 1 & & & & & & \\
\hline Participation & & & & & & 1 & & & & \\
\hline
\end{tabular}


As shown in Table III, all teachers made direct requests for information, and they tended to make direct requests for want/need. They made indirect requests for suggestion and desire/wish, and they made both direct and indirect requests for control and encouragement, and most teachers made direct and indirect requests for speculation. These findings also showed that the teachers made indirect requests for comprehension, confirmation, offer, curiosity, greetings. However, their frequencies of occurrences were comparatively lower.

Table IV shows the frequencies of the pragmatic functions of requests performed by students. The findings showed that the students also performed various pragmatic functions of requests, including requests for clarification, want/need, permission, desire/wish, suggestion, help, curiosity, confirmation, offer, and advice.

TABLE IV: FREQUENCIES OF PRAGMATIC FUNCTIONS OF REQUESTS

\begin{tabular}{|c|c|c|c|c|c|c|c|c|c|}
\hline \multicolumn{10}{|c|}{ PERFORMED BY STUDENTS } \\
\hline & A & $\mathrm{B}$ & & $\mathrm{C}$ & & $\mathrm{D}$ & & $\mathrm{E}$ & \\
\hline & I & $\mathrm{D}$ & I & $\mathrm{D}$ & I & $\mathrm{D}$ & $\mathrm{I}$ & $\mathrm{D}$ & $\mathrm{I}$ \\
\hline & 7 & 10 & 20 & 1 & 10 & 4 & 2 & 16 & 16 \\
\hline & $\%$ & $\%$ & $\%$ & $\%$ & $\%$ & $\%$ & $\%$ & $\%$ & $\%$ \\
\hline Clarification & 43 & 60 & 40 & & 20 & & 50 & 44 & 38 \\
\hline Want/Need & 14 & 30 & 40 & & 30 & 75 & 50 & 56 & 44 \\
\hline Permission & 14 & & 5 & & & 25 & & & \\
\hline Desire/Wish & 29 & & 5 & & & & & & \\
\hline Suggestion & & & 5 & & & & & & \\
\hline Help & & 10 & & & & & & & \\
\hline Curiosity & & & 5 & & & & & & \\
\hline Confirmation & & & & & 30 & & & & \\
\hline Offer & & & & 100 & 20 & & & & \\
\hline Advice & & & & & & & & & 18 \\
\hline
\end{tabular}

D means direct requests and I means indirect direct

As shown in Table IV, the students made a higher frequency of requests for want/need and clarification. In particular, these pragmatic functions of requests were performed by students in all classes. The students performed these pragmatic functions by making direct and/or indirect requests. These students make a higher frequency of requests for want/need and clarification. As [7] notes, classrooms are considered as a communication system where teachers and students being social actors use language for attaining communicative purposes, so not surprisingly, they both make requests with these pragmatic functions in a manner quite similar to those of speakers outside the classroom.

\section{CONCLUSION}

The results of the study found that all teacher and student participants made various types of requests for performing different pragmatic functions in the English classrooms. As requesting is a sociolinguistic behavior, it is suggested that teachers consider classrooms as a social context similar to the contexts outside the classroom and encourage students to make requests as well as perform the pragmatic functions in requests appropriately and consciously. To make teaching and learning effective, it is suggested that college EFL teachers make requests for communicative purposes in the classrooms. The present study makes some suggestions for further research. First, to make the results of the study more generalizable, there is a need to take the subject and the gender factor into consideration. That is, more male and female teacher participants and more student participants at different English proficiency levels can be invited for future research. Second, the request types in terms of directness level can be divided into subcategories for understanding the complex processes of teachers' and students' requesting behaviors in the English classrooms. Specifically, the request types can be further sub-categorized into various interaction media types, including verbal requests, non-verbal requests, and rhetorical requests, and into various response types, including unison responses, group responses and individual responses. These subcategorizations may help the future researchers draw a more vivid picture of what really is going on in the classroom teachers' and students' requesting behaviors during the classroom sessions.

\section{APPENDIX}

FRAMEWORK OF ANALYSIS

\begin{tabular}{|c|c|}
\hline \multicolumn{2}{|c|}{ Types of Requests in College EFL classrooms } \\
\hline $\begin{array}{l}\text { Teacher requests } \\
\text { Directness level types: } \\
\text { types of requests in terms of } \\
\text { directness levels } \\
\text { (1) Direct request } \\
\text { - Imperative } \\
\text { - Unhedged performative } \\
\text { - Hedged performative } \\
\text { - Locution derivable } \\
\text { - Want statement } \\
\text { - Elliptical phrase } \\
\text { (2) Indirect request } \\
\text { - Suggestory formula } \\
\text { - Query preparatory } \\
\text { - Desire/Wish } \\
\text { - Strong hint } \\
\text { - Mild hint }\end{array}$ & $\begin{array}{l}\text { Student requests } \\
\text { Directness level types: } \\
\text { types of requests in terms of } \\
\text { directness levels } \\
\text { (1) Direct request } \\
\text { - Imperative } \\
\text { - Unhedged performative } \\
\text { - Hedged performative } \\
\text { - Locution derivable } \\
\text { - Want statement } \\
\text { - Elliptical phrase } \\
\text { (2) Indirect request } \\
\text { - Suggestory formula } \\
\text { - Query preparatory } \\
\text { - Desire/Wish } \\
\text { - Strong hint } \\
\text { - Mild hint }\end{array}$ \\
\hline \multicolumn{2}{|c|}{ Pragmatic Functions of Requests Performed in College EFL Classrooms } \\
\hline $\begin{array}{l}\text { Teacher requests } \\
\text { 1. Request for information } \\
\text { 2. Request for confirmation } \\
\text { 3.Request for comprehension } \\
\text { 4.Request for clarification } \\
\text { 5.Request for performing a task } \\
\text { 6. Request for obligation } \\
\text { 7. Request for willingness } \\
\text { 8. Request for offer } \\
\text { 9. Request for suggestion } \\
\text { 10.Request for control } \\
\text { 11.Request for advice } \\
\text { 12.Request for ability } \\
\text { 13.Request for wishes } \\
\text { 14.Request for speculation } \\
\text { 15.Request for encouragement } \\
\text { 16.Request for needs } \\
\text { 17.Request for order } \\
\text { 18.Request for attention } \\
\text { 19.Request for greetings } \\
\text { 20.Request for cooperation } \\
\text { 21.Request for help } \\
\text { 22.Request for control }\end{array}$ & $\begin{array}{l}\text { Student requests } \\
\text { 1.Request for information } \\
\text { 2.Request for confirmation } \\
\text { 3.Request for clarification } \\
\text { 4.Request for needs } \\
\text { 5.Request for wishes } \\
\text { 6.Request for curiosity } \\
\text { 7.Request for offer } \\
\text { 8.Request for suggestion } \\
\text { 9.Request for ability } \\
\text { 10.Request for willingness } \\
\text { 11.Request for permission } \\
\text { 12.Request for help }\end{array}$ \\
\hline
\end{tabular}

\section{ACKNOWLEDGMENT}

Chiung-Chiuen Chen thanks Dr. David S.D. Tseng for his great help and excellent feedback in this study.

\section{REFERENCES}

[1] S. Blum-Kulka, J. House, and G. Kasper, "Investigating cross-cultural pragmatics: An introductory overview," in Cross-cultural Pragmatics: 
Requests and Apologies, S. Blum-Kulka, J. House, and G. Kasper, Eds. Norwood, NJ: Ablex, 1989, pp. 1-34.

[2] M. C. Yu, “A study of Taiwanese college students' performance of pragmatic behaviors in an L2 and their psychological processes (Part 1)," A Final Report of a National Science Council Project, Department of English, National Chengchi University, 2003.

[3] P. Grundy, Doing Pragmatics, 3rd Ed. London: Hodder Education, 2008.

[4] Y. H. Lin, "Query preparatory modals: Cross-linguistic and cross-situational variations in request modification," Journal of Pragmatics, vol. 41, pp. 1636-1656, 2009.

[5] Z. R. Eslami and K. D. McLeod, "It's 8 o'clock in the morning- are you watching television? Teaching indirect requests," in Pragmatics from Research to Practice: Teaching Speech Acts, D. H. Tatsuki and N. R. Houck, Eds. Alexandria, Virginia: Teachers of English to Speakers of Other Languages, Inc., 2010, pp. 19-26.

[6] R. Ellis, "Learning to communicate in the classroom: A study of two learners' requests," Studies in Second Language Acquisition, vol. 14 pp. 1-23, 1992

[7] C. B. Cazden, Classroom Discourse: The Language of Teaching and Learning, Oxford: Heinemann, 2001

[8] C. Dalton-Puffer, "Negotiating interpersonal meanings in naturalistic classroom discourse: Directives in content and language integrated classrooms," Journal of Pragmatics, vol. 37, pp. 1275-1293, 2005.

[9] C. Doughty et al., "Information gap tasks: Do they facilitate second language acquisition?" TESOL Quarterly, vol. 20, pp. 305-325.

[10] S. Blum-Kulka, "Interpreting and performing speech acts in a second language - a cross-cultural study of Hebrew and English," in Sociolinguistics and Language Acquisition, N. Wolfson and E. Judd, Eds. Rowley, MA: New House Publishers, Inc., 1983, pp. 36-55.

[11] P. Brown and S. C. Levinson, Politeness: Some Universals in Language Usage, Cambridge: Cambridge University Press, 1987.

[12] G. Kasper and S. Blum-Kulha, Interlanguage Pragmatics, New York: Oxford University Press, 1993.

[13] E. Weizman, "Interlanguage requestive hints," in Interlanguage pragmatics, G. Kasper and S. Blum-Kulha, Eds. New York: Oxford University Press, 1993, pp. 123-137.

[14] K. Rose and G. Kasper, Pragmatics in Language Teaching, New York: Cambridge University Press, 2001.

[15] G. Schauer, Interlanguage Pragmatic Development: The Study Abroad Context, NY: Continuum International Publishing Group.

[16] M. Economidou-Kogetsidis, "Cross-cultural and situational variation in requesting behaviour: Perceptions of social situations and strategic usage of request patterns," Journal of Pragmatics, vol. 42, pp. 2262-2281, 2010.

[17] S. Blum-Kulka and E. Olshtain, "Requests and apologies: A cross-cultural study of speech act realization patterns (CCSARP)," Applied Linguistics, vol. 5, no. 3, pp. 196-212, 1984.

[18] S. Fukushima, "Offers and requests: Performance by Japanese learners of English," World Englishes, vol. 9, pp. 317-325, 1990.

[19] T. Hill, "The development of pragmatic competence in an EFL context," Ph.D. dissertation, Temple University, Japan, 1997.

[20] M. Economidou-Kogetsidis, "Interlanguage request modification: The use of lexical/phrasal downgraders and mitigating supportive moves," Multilingua, vol. 28, pp.79-112, 2009.

[21] X. J. Yang, Pragmatic Development in a Second Language: A Cross-Sectional Study on the Acquisition of English Requests by Chinese Learners, Beijing: Defense Industry Press, 2009.

[22] C. Lee, "Strategy and linguistic preference of requests by Cantonese learners of English: An interlanguage and crosscultural comparison," Multilingua, vol. 30, pp. 99-129, 2011.

[23] A. Trosberg, Interlanguage Pragmatics: Requests, Complaints and Apologies, Berlin, Germany: Walter de Gruyter \& Co, 1995.

[24] Y. C. Lee, "Comparison of politeness and acceptability perceptions of request strategies between Chinese learners of English and native English speakers," Asian Social Science, vol. 7, no. 8, pp. 21-35, 2011.

[25] M. C. Yu, "A study of Taiwanese college students' performance of pragmatic behaviors in an L2 and their psychological processes (Part 2)," A Final Report of a National Science Council Project, Department of English, National Chengchi University, 2004.

[26] S. Mizon, "Teacher talk: A case study from the Bangalore/Madras communication ELT project," M.S. Thesis, University of Lancaster, 1981.

[27] M. Early, "Input and interaction in content classrooms: Foreigner talk and teacher talk in classroom discourse," $\mathrm{PhD}$. dissertation, University of California, Los Angeles, 1985

[28] T. Pica and M. Long, "The linguistic and conversational performance of experienced and inexperienced teachers," in Talking to Learn:
Conversation in Second Language Acquisition, R. Day, Ed. Rowley, Mass: Newbury House, 1986, pp. 85-98.

[29] W. Lörscher and R. Schulze, "On polite speaking and foreign language classroom discourse," International Review of Applied Linguistics in Language Teaching, vol. 26, no. 3, pp. 183-199, 1988

[30] C. Falsgraf and D. Majors, "Implicit culture in Japanese immersion classroom discourse," Journal of the Association of Teachers of Japanese, vol. 29, no. 2, pp. 1-21, 1995.

[31] C. Chaudron, Second Language Classrooms: Research on Teaching and Learning, Cambridge: Cambridge University Press, 1988.

[32] R. Cullen, "Teacher-talk and the classroom context," ELT Journal, vol. 52, pp. 179-187, 1998

[33] M. Zohrabi et al., "Teachers' use of display vs. referential questions across different proficiency levels," International Journal of Applied Linguistics \& English Literature, vol. 3, no. 2, pp. 96-100, 2014

[34] M. H. Long and C. J. Sato, "Classroom foreigner talk discourse: Forms and functions of teachers' questions," TESOL Quarterly, vol. 15, pp. 26-30, 1983

[35] D. S. D. Tseng, "Adding a third language: An in-depth analysis of the teacher questioning processes in a Chinese classroom," $\mathrm{PhD}$ dissertation, University of Pennsylvania, Pennsylvania, USA, 1992.

[36] P. Duff, "Another look at interlanguage talk," in Talking to Learn: Conversation in Second Language Acquisition, R. Day, Ed. Rowley, Mass: Newbury House, 1986, pp. 147-181.

[37] K. Rulon and J. McCreary, "Negotiation of content: Teacher-fronted and small group interaction," in Talking to Learn: Conversation in Second Language Acquisition, R. Day, Ed. Rowley, Mass: Newbury House, 1986, pp. 182-199.

[38] X. Y. Tan, The Framework and Strategies of Quality Questioning in Language Teaching: A Study of Cognitive Pragmatic Perspective (in Chinese), Kunming: Yunnan University Press, 2012.

[39] O. F. David, "Teacher's questing behaviors and ESL classroom interaction pattern," Humanity and Social Sciences, vol. 2, no. 2, pp. 127-131, 2007.

[40] N. Shomoossi, "The effect of teachers' questioning behavior on EFL classroom interaction: A classroom research study," The Reading Matrix, vol. 4, pp. 96-104, 2004.

[41] C. F. Chen, "A study of EFL teachers' beliefs in questioning strategy use in industrial vocational senior high schools," M.S. thesis, Providence University, Taiwan, 2011.

[42] J. Zuengler, "Many lessons from a school: What classroom discourse analysis reveals," Language Teaching, vol. 44, no. 1, pp. 55-63, 2011

[43] Y. F. Chang, "Refusing in a foreign language: An investigation of problems encountered by Chinese learners of English," Multilingua, vol. 30, pp. 71-98, 2011

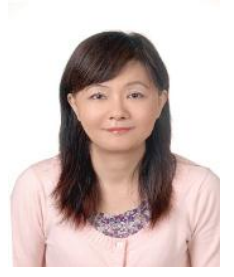

Chiung-Chiuen Chen was born in Taichung, Taiwan. She completed her doctor's degree in linguistics and English language teaching at National Changhua University of Education (NCUE) of Taiwan in 2015. She is currently a part-time assistant professor of English Department at NCUE. Her major research interests focus on oral communication in an L2, classroom interaction, and L2 learners' pragmatic competence development.

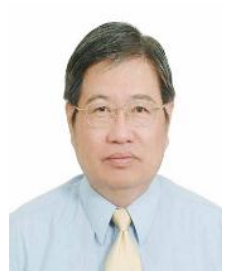

David S. D. Tseng was born in Kaohsiung, Taiwan in 1949. He completed his Ph.D. degree at University of Pennsylvania, Philadelphia, Pennsylvania, USA in 1992, specializing in educational linguistics. Since 1977, he had been teaching at the English Department of National Changhua University of Education (NCUE), Changhua City, Taiwan for more than thirty years. After retiring from NCUE in 2006, he had been recruited at the Department of Foreign Language and Literature, Asia University, in Wu-feng, central Taiwan for four years, and then transferred to Providence University (PU), Taichung, Taiwan in 2010. Since then, he has been teaching at the Department of Foreign Language, Literature and Linguistics at PU as a full-time professor of English. He has published some books and many papers mostly in locally-held international conferences in Taiwan. His recent publication was English Teaching: What to Teach and How (in Chinese), (Taipei, Taiwan: The Taiwan ELT Publishing Co., Ltd., 2014). His interests include classroom interaction and discourse analysis, English teaching materials and methodology, English writing instruction and research, English teaching: theory and practice, English teacher training and assessment, and English semantics and pragmatics. 